\title{
Confused reference in the article entitle: pharmacogenomics of platinum-based chemotherapy in non-small cell lung cancer-focusing on DNA repair systems
}

\author{
Bo Yuan Wang ${ }^{1} \cdot$ Qiu Shi Zhang ${ }^{1} \cdot$ Ying Luo ${ }^{1}$
}

Received: 16 March 2017/Accepted: 4 April 2017/Published online: 25 April 2017

(C) Springer Science+Business Media New York 2017

We read with great interest the study by Xiong et al. [1]. Yi Xiong et al. focus on the single nucleotide polymorphism (SNP) of non-small cell lung cancer (NSCLC) and DNA repair pathway based on the view of pharmacogenomics in NSCLC. And they discussed the relationship between the variation of DNA repair genes and the platinum-based chemotherapy in NSCLC treatment.

However, in the Yi Xiong et al.'s study, we found errors which should be checked and corrected. Firstly, Yi Xiong et al. confused the data of first [2] cite with second [3] cite, in the Reck et al.'s study (the first one), the number of deaths from lung cancer representing $19 \%$ of all cancer death in 2010 [2]. It is notable that Yi Xiong et al. only used Khuri's data [3], but cited both of them. And another mistake is the short form of non-small cell lung cancer is NSCLC, not NSCLS.
Compliance with ethical standards

Conflict of interest The authors declare that they have no conflicts of interest.

Ethical approval This article does not contain any studies with human participants or animals performed by any of the authors.

\section{References}

1. Xiong Y, Huang BY, Yin JY. Pharmacogenomics of platinumbased chemotherapy in non-small cell lung cancer: focusing on DNA repair systems. Med Oncol. 2017;34(4):48. doi:10.1007/ s12032-017-0905-6.

2. Reck M, Heigener DF, Mok T, Soria JC, Rabe KF. Management of non-small-cell lung cancer: recent developments. Lancet. 2013;382(9893):709-19. doi:10.1016/S0140-6736(13)61502-0.

3. Khuri F. Lung cancer and other pulmonary neoplasms. Goldman's Cecil Medicine. 25th ed. Philadelphia: Elsevier Saunders; 2016.

Ying Luo

yingluo@kmust.edu.cn

1 Faculty of Life Science and Technology, Kunming

University of Science and Technology, 727 South Jing Ming

Road, Chenggong County,

Kunming 650500, Yunnan Province, China 